\title{
BIONIC EYE AND CREATE ARTIFICIAL VISION
}

\author{
Khadijeh moulaei
}

MSc Student of Medical Informatics, Iran University of Medical Sciences, Tehran, Iran.

Correspondence:

Tel: +98.09189480637, E-mail: moulaei.kh91@gmail.com

\section{TYPE OF ARTICLE: CONFERENCE ABSTRACT}

\begin{abstract}
Introduction: There are nearly 40 million cases of blindness in the worldwide, and 124 million people have been affected by low vision. For this reason, researchers are intent on developing new ways to restore vision. One of these efforts was the offer of an innovation called the bionic eye.

Methods: This study is a literature review, which aims to provide a modern technology called bionic eye; it is for people who are blind due to retinitis pigmentosa and macular degeneration.

Results: The visual system is much more complex than the auditory system and other systems of the body. Hence, the system is facing more challenges for the loss of vision capability. Retinitis pigmentosa and macular degeneration are a group of inherited diseases of the retina. The two types of rods and cones of the retina diseases will be causing loss of peripheral vision or total blindness. Hence, to restore the sight of these two groups, the blind can use the bionic eye with retinal prosthesis. Despite advances in technology, the bionic eyes for the blind with two pigmentosa and macular degeneration has not provided the perfect solution for the challenges of other eye diseases.

Conclusion: Nowadays, artificial devices are being developed to replace the destroyed body members. The researchers are using these devices to combat disease. One of these artificial devices is the bionic eye, which has enabled blind people to perform daily tasks and has changed their world. But, due to the limitations of these devices, they cannot be introduced as an alternative to the normal human eye because they do not have the ability to restore vision to a natural state. Certainly in the near future, using the bionic eye with a number of electrodes and abilities will be presented for blind people to help them see images with higher quality, better resolution, and even more realistic colors.

KEYWORDS: Bionic eye, Retinal prosthesis, Retinitis pigmentosa, Macular degeneration
\end{abstract}

\footnotetext{
Abstracts of First National Congress of Medical Informatics, Mashhad, Iran, February 2017

(C) 2017 The Authors. This is an open access article under the terms of the Creative Commons Attribution-NonCommercialNoDerivs License, which permits use and distribution in any medium, provided the original work is properly cited, the use is non-commercial and no modifications or adaptations are made.
} 